\title{
Screening of carotenoid-producing Rhodotorula strains isolated from natural sources
}

\author{
Jana Tkáčová, Katarína Furdíková, Tatiana Klempová, \\ Katarína Ďurčanská, Milan Čertík \\ Department of Biochemical Technology, Faculty of Chemical and Food Technology, \\ Slovak University of Technology in Bratislava, \\ Radlinského 9, SK-812 37, Bratislava, Slovak republic \\ jana_tkacova@stuba.sk
}

\begin{abstract}
Carotenoids represent large group of various natural pigments ensuring typical coloration of plants, microorganisms and several animals. It was confirmed by many studies, that consuming these biological active compounds has positive impact for human life. Therefore, they are applied in different industrial fields, such as pharmacy, cosmetic, food, and feed industry. Due to high demand for carotenoids we would like to discover new microorganisms overproducing carotenoids. We focused on yeasts of genus Rhodotorula sp. (forty isolates), that we screened according to growth and carotenoid production on Petri dishes and production media. After cultivation on Petri dishes we selected five strains (denoted as KF-4, KF-6, KF-24, KF-31, KF-104) with interesting pigment production and quick growth. The secondary screening on production media identified $\mathrm{KF}-104$ as the best producer of carotenoid pigments with massive pigment accumulation $(1.15 \mathrm{mg} / \mathrm{g}$ DCW) and yield $(9.69 \mathrm{mg} / \mathrm{L})$. The main carotenoid of $\mathrm{KF}-104$ isolate was $\beta$-carotene $(35.4 \%)$ with the accumulation of $408.7 \mu \mathrm{g} / \mathrm{g}$ DCW and the yield of $3.4 \mathrm{mg} / \mathrm{L}$. The rest were torularhodin, torulene and $\gamma$-carotene $(62.7-79.0 \%)$. Production of torularhodin in the cells was low $(0.4$ to $1.4 \mathrm{mg} / \mathrm{L})$ as was its accumulation in cells $(31.2-121.0 \mu \mathrm{g} / \mathrm{g} \mathrm{DCW})$. We continue the experimental analyses of these isolates in order understand differences in the content of individual pigments.
\end{abstract}

Keywords: carotenoids, microbial pigment production, Rhodotorula sp., yeast

\section{Introduction}

Carotenoids are important natural pigments of red, orange and yellow colours, which are widely used in the commercial sector. Carotenoids are terpenoid C40 pigments synthesized from two molecules of a geranylgeranyl pyrophosphate by the enzyme pyrophosphate transferase. Based on their structure, they are divided into carotenes and xanthophylls. Carotene chain consists of carbon and hydrogen ( $\beta$-carotene, torulene), while xanthophylls bound oxygen in the functional group as hydroxy, oxy or carboxy group (astaxanthin, cataxanthin; Bhosale and Bernstein, 2005; Kim and DellaPenna, 2006; Krinsky and Johnson, 2005). Up to these days over 700 carotenoids, especially C40 terpenoids with different number of double bonds, and terminal structures of oxygen-containing functional groups were identified (Britton et al., 2004; Jin et al., 2010).

Carotenoids provide great health benefits for human health due to their antioxidant activity. Carotene and other structurally related compounds serve as precursors of vitamin $\mathrm{A}$ and are important in the immune response and cell differentiation (Ribeiro et al., 2011; Ye and Bhatia, 2012). Their positive health effects provide protection against ischemic heart disease and eye diseases. Many studies have established that carotenoids prevent formation of various types of cancer (Giovannucci et al., 1995; Mayne, 1996). Furthermore, they are applied in food industry as a colouring of fish, squid and eggs (Ye and Bhatia, 2012). For example, $\beta$-carotene and astaxanthin are applied in industry as natural food colourants and forage additives in agriculture (Bhosale and Gadre, 2001; Mantzouridou et al., 2002).

Natural pigments are industrially obtained by a) biotechnological processes using pigment-forming microorganisms, or b) from plant materials. Unfortunately, global pigment production from natural sources represents only $2 \%$ (Voutilainen et al., 2006). Biotechnological approach covers several microbial producers such as yeasts, fungi, bacteria and algae. Yeast carotenoid-producers are mainly represented by strains belonging to genus Rhodotorula sp., Rhodosporidium sp. and Sporobolomyces sp. for synthesis of $\beta$-carotene, $\gamma$-carotene, torulene and torularhodin, and Xanthophylomyces sp. for formation of astaxanthin (Frengova and Beshkova, 2009; Yurkov et al., 2008). Filamentous fungi, such as Gibberela sp., Mucor sp., Blakeslea sp. 
and Phycomyces sp. are characterized by a significant $\beta$-carotene formation ( $\mathrm{Xu}$ et al., 2007). Bacteria are typical for the production of canthaxanthin. The most studied bacteria producing pigments are: Pantoea sp., Corynebacterium sp., Microcococcus sp., Brevibacterium sp., Bradyrhizobium spp., Gordonia $s p$. and Dietzia sp. (Nasri-Nasravadi and Razavi, 2010). Microalgae classified into group Chlorophycae (Chlorella sp., Dunaliella sp. a Haematococcus sp.) have also been applied for commercial production of pigments (Fores et al., 2010).

Genus Rhodotorula sp. constitutes a group of strictly aerobic yeast. They are characterized by the production of glycogen metabolism during the exponential growth phase and large amounts of lipids and pigments during the stationary phase. R. glutinis has wide application in the food industry for its biotechnological potential and health harmlessness (Dworecka-Kaszak and Kizerwetter-Swida, 2011; Reiss et al., 2012).

The aim of the work was to screen new potential yeast producers of carotenoid pigments from natural sources. Therefore, 40 yeast isolates previously identified as Rhodotorula species were picked up from vegetative parts of three vine varieties and analysed for their growth and ability to synthesize carotenoid pigments.

\section{Material and methods}

\section{Isolation, cultivation, and screening of Rhodotorula isolates}

Forty yeast cultures identified as Rhodotorula species (marked as KF strains) were tested in this study. Yeast strains were isolated from different vegetative parts of vine: old and one-year-old wood, leaves, and fruits. Vine samples used as the source of pigment producing yeasts originated in vineyard Horné Trávniky belonging to winegrowing region Modra, Small Carpathians Wine Region, Slovakia. For isolation three vine varieties were used: Rizling vlašský (Welsch Rizling), Muškát moravský (Moravian muscat) and Veltlínske zelené (Grüner Veltliner). Rhodotorula species were stored in Petri dishes with $7 \%$ malt agar for 4 days at $25{ }^{\circ} \mathrm{C}$ and subsequently were re-inoculated in the $20 \mathrm{~mL}$ of culture media with $30 \mathrm{~g} / \mathrm{L}$ glucose and $5 \mathrm{~g} / \mathrm{L}$ yeast extract (YG medium). Cultures were cultivated for 5 days in rotary incubator at $140 \mathrm{rpm}$ and $25^{\circ} \mathrm{C}$ under constant yellow light. Finally, KF strains were selected by primary and secondary screening. Colour of colonies on Petri dishes and cell growth speed represented criteria for primary screening and total pigment content (TP) was parameter for secondary screening.

\section{Lipid and carotenoid extraction and purification}

For lipid and pigment isolation, the biomass was washed by saline and distilled water. We used modified procedure of Folch et al. (1957). Biomass was homogenized in the mortar with sea sand. Lipophilic compounds were double extracted by Folch mixture (chloroform/methanol 2:1 (v/v)) for $2 \mathrm{~h}$ at laboratory temperature with occasional stirring. After extraction the mixture was filtered to remove cells and the extracts were mixed with distilled water (1.2-fold of total extract volume). The mixture was stirred vigorously for 1 minute and centrifuged to effect phase separation. The chloroform layer containing lipids and pigments was filtered through anhydrous $\mathrm{Na}_{2} \mathrm{SO}_{4}$ and evaporated under vacuum. Lipid extract with carotenoid pigments was re-suspended in the $1 \mathrm{~mL}$ mixture of hexane:chloroform $=9: 1$ and analysed by high-performance liquid chromatography (HPLC).

\section{HPLC carotenoid analysis}

Carotenoid extract was analysed by high-performance liquid chromatography (HP 1100, Agilent). Volume of $10 \mu \mathrm{L}$ of carotenoid extract was injected into the column (LiChrospher ${ }^{\circledR}$ 100 RP-18, Mercx) and carotenoid content and composition was analysed by HPLC with DAD detector. The conditions of analyses were as follows: flow rate of solvents (solvent $\mathrm{A}$ - acetonitrile:water: formic acid in the ratio 86:10:4 vol.; solvent B ethyl acetate:formic acid in the ratio 96:4 vol.) was $1 \mathrm{ml} / \mathrm{min}$ with a gradient of $100 \% \mathrm{~A}$ at $0 \mathrm{~min}$, $100 \% \mathrm{~B}$ at $20 \mathrm{~min}$ and $100 \% \mathrm{~A}$ at $30 \mathrm{~min}$. Carotenoid pigments were identified using known standard samples and records were evaluated by ChemStation B 0103 (Agilent Technologies). The records were quantified by retention times of known carotenoid standards (Sigma, Germany), which were measured under the same conditions as the sample.

\section{Results and discussion}

\section{Isolation of KF strain}

Although Rhodotorula has no oenological importance, it is the part of natural yeast micro-flora of vine and occurs all over the year on the plants. Most of isolated Rhodotorula strains were collected from vine organs during early spring (Furdíková et al., 2011) when climatic conditions were not hospitable and vine only began to sprout. Forty strains of Rhodotorula were isolated by classical microbiological isolation techniques and characterised and identified based on their microscopic, macroscopic, physiological and biochemical characteristics (Furdíková et al., 2012). 


\section{Primarily screening of yeasts on Petri dishes}

In order to select the best candidates for pigment production, primary screening based on growth speed and colonies colour was carried out on Petri dishes. It is widely accepted that an average cultivation time of Rhodotorula sp. on Petri dishes is 4 days. From 40 yeast isolates only 5 strains were capable of such rapid growth, and therefore they could be used for cultivation in production media (YG media).

Other crucial factors for selection of pigmentforming yeasts grown on Petri dishes were colour of colonies and colour intensity of colonies. These data are summarized in Table 1 where colour intensity from low to high was marked by number of small crosses (from 1 to 5). KF-104 strain with crimson red colour implied as an appropriate for carotenoid overproduction in pursuance of colour intensity and the colony colour. These two parameters indicated enhancement of pigment synthesis and the high total pigment content in comparison with other strains.

Tab. 1. Description of colour intensity and colour type of cell colonies.

\begin{tabular}{lcc}
\hline Strain & colour intensity & colour hue \\
\hline KF-4 & ++++ & salmon-red \\
KF-6 & +++ & salmon-red \\
KF-24 & ++++ & coral red \\
KF-31 & ++ & orange-red \\
KF-104 & +++++ & crimson red \\
\hline
\end{tabular}

\section{Growth of pigment forming yeasts in liquid media}

Five selected Rhodotorula strains according to their growth and capacity to form pigment colour on Petri dishes were tested in flask experiments in liquid media. Cultivation period was set for 5 days with subsequent determination of dry cell weight (DCW) and residual glucose. Glucose as a carbon source was totally consumed by 5 selected $\mathrm{KF}$ strains within 5 days (data not shown). However, the amount of biomass varied widely among individual strains and the best growth (expressed as DCW) was detected for KF-4 (11.9 g/L) and KF$24(11.6 \mathrm{~g} / \mathrm{L})$, respectively. On the other hand, the minimum biomass yield $(7.9 \mathrm{~g} / \mathrm{L})$ was obtained for KF-104 strain (Fig. 1A). Screening of Rhodotorula strains by El-Banna et al. (2012) resulted in finding the potential carotenoid yeast with similar growth $11.5 \mathrm{~g} / \mathrm{L}$. Because Rhodotorula strains are considered as oleaginous, lipid accumulation in the yeast cells was also determined. As Fig. 1B indicates, all strains accumulated from 10 to $20 \%$ of lipids in yeast biomass. The strain KF-6 showed the best capacity to synthesize lipids (20\%), while the strain KF-4 formed only $11 \%$ lipids in the biomass.

\section{Production of carotenoid pigments \\ by yeasts in liquid media}

As mentioned above, yeasts belonging to Rhodotorula species are known as useful producers of carotenoid pigments (Frengova and Beshkova, 2009). In this study, selected Rhodotorula strains were tested for total production of carotenoids, their accumulation in the cells as well as the analysis of pigments composition. From the biotechnological point of view, the total carotenoid yield expressed as $\mathrm{mg} / \mathrm{L}$ is one of the most important factor for the selection of carotenoid-forming yeast.

The maximal yield of total carotenoids $(9.7 \mathrm{mg} / \mathrm{L})$ was found for the KF-104 strain (Fig. 2A). Other tested strains are characterized by significantly

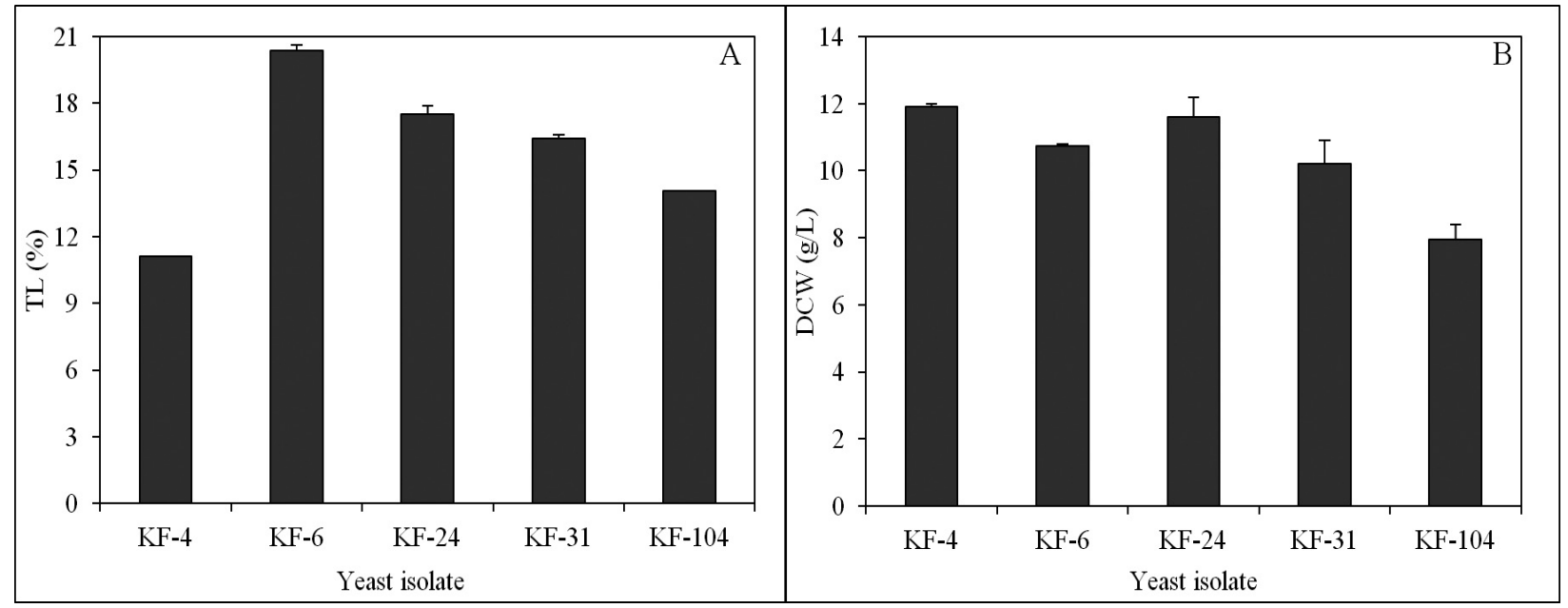

Fig. 1. A) Amount of dry cell weight (DCW, g/L);

B) lipid accumulation (TL, \%) after 5 days of cultivation. 


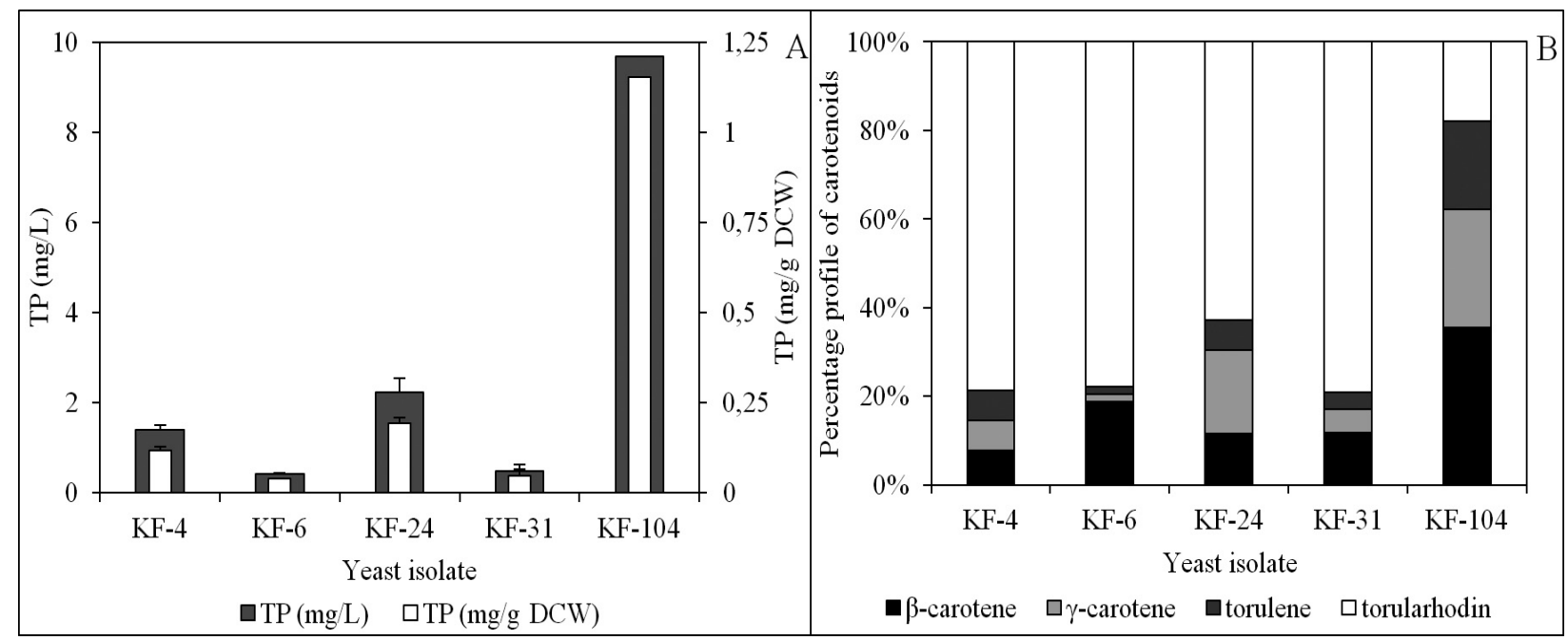

Fig. 2. A) Yield (mg/L) and accumulation (mg/g DCW) of carotenoids in the cell membranes; B) Percentage profile of carotenoid pigments.

TP-total pigments.

lower capacity to form pigments and their yield varied from 0.4 to $2.3 \mathrm{mg} / \mathrm{L}$. Such high yield of carotenoids by strain KF-104 was obviously due to up 10 times higher capacity to accumulate pigments in the cells $(1.15 \mathrm{mg} / \mathrm{g}$ cells $)$ compare to other yeasts (0.05-0.19 mg/g cells). Thus, although growth of the strain KF-104 was only $7.9 \mathrm{~g}$ biomass/L, the effective biochemical machinery for biosynthesis of carotenoids and their accumulation in the cells resulted in selection of the KF-104 as the best candidate for pigment production of tested Rhodotorula strains. Species of the genus Rhodotorula sp. (Rhodotorula glutinis, Rhodotorula minuta, Rhodotorula mucilaginosa and Rhodotorula graminis) were also tested by several researchers for the production of $\beta$-carotene, $\gamma$-carotene, torulene and torularhodin (Aksu and Eren, 2005; Buzzini et al., 2005; Maldonade et al., 2008; Tinoi et al., 2005). They described maximal carotenoid accumulation up to $330 \mu \mathrm{g}$ per gram of cell biomass during 6-7 days of fermentation.

Compositional analysis of total pigments extracted from five Rhodotorula isolates showed that all strains consisted of 4 main carotenoids: $\beta$-carotene, $\gamma$-carotene, torulene and torularhodin. It is interesting, that while torularhodin was the main pigment in strains KF-4, KF-6, KF-24 and KF31 (62.7-79.0\% from all carotenoids), the strain KF-104 synthesized only $18 \%$ torularhodin (Fig. $2 \mathrm{~B})$. In contrast, $\beta$-carotene $(35.4 \%)$ and $\gamma$-carotene $(26.7 \%)$ were principal pigments in the strain KF104. Carotenoids in these yeasts are synthesized from lycopene to $\gamma$-carotene that serves as precursor form other pigments. Then $\gamma$-carotene is metabolised to $\beta$-carotene via lycopene cyclase and to torulene through desaturation. Subsequently, torulene is converted to torularhodin by hydroxylase and ketolase (Schmidt-Dannert, 2000). The reason why the strain KF-104 prefers the $\beta$-carotene pathway prior to torulene/ torularhodin pathway remains to be answered.

In any case, such different structural distribution of individual carotenoids by studied yeasts resulted in their diverse total yields and accumulation in the cells (Table 2). The best pigment producer KF-

Tab. 2. A) Percentage profile of carotenoid pigments; B) Carotenoid yield (mg/L) and accumulation of main pigments in cell membrane $(\mu \mathrm{g} / \mathrm{g}$ DCW $)$.

\begin{tabular}{lcccccccc}
\hline Sample & $\begin{array}{c}\text { Bcar } \\
\mathrm{mg} / \mathrm{L}\end{array}$ & $\begin{array}{c}\text { Gcar } \\
\mathrm{mg} / \mathrm{L}\end{array}$ & $\begin{array}{c}\text { Thr } \\
\mathrm{mg} / \mathrm{L}\end{array}$ & $\begin{array}{c}\text { Trl } \\
\mathrm{mg} / \mathrm{L}\end{array}$ & $\begin{array}{c}\text { Bcar } \\
\mu \mathrm{g} / \mathrm{g} \text { DCW }\end{array}$ & $\begin{array}{c}\text { Gcar } \\
\mu \mathrm{g} / \mathrm{g} \text { DCW }\end{array}$ & $\begin{array}{c}\text { Trl } \\
\mu \mathrm{g} / \mathrm{g} \text { DCW }\end{array}$ & $\begin{array}{c}\text { Thr } \\
\mu \mathrm{g} / \mathrm{g} \text { DCW }\end{array}$ \\
\hline KF-4 & 0.12 & 0.10 & 0.10 & 1.11 & 8.62 & 7.99 & 7.98 & 93.23 \\
KF-6 & 0.08 & 0.01 & 0.01 & 0.34 & 7.49 & 0.67 & 0.67 & 31.19 \\
KF-24 & 0.26 & 0.42 & 0.12 & 1.41 & 22.09 & 35.89 & 13.34 & 121.02 \\
KF-31 & 0.06 & 0.03 & 0.02 & 0.38 & 2.65 & 2.65 & 1.86 & 37.99 \\
KF-104 & 3.43 & 2.59 & 1.92 & 1.74 & 408.69 & 308.08 & 228.89 & 207.58 \\
\hline
\end{tabular}

Abbreviations: Bcar - $\beta$-carotene, Gcar - $\gamma$-carotene, Thr - torularhodin, Trl - torulene. 
104 formed $3.43 \mathrm{mg} \beta$-carotene /L and $2.59 \mathrm{mg}$ $\gamma$-carotene $/ \mathrm{L}$. Also accumulation of $\beta$-carotene and $\gamma$-carotene in the KF-104 cells reached values $408.7 \mu \mathrm{g} / \mathrm{g}$ DCW and $308.8 \mu \mathrm{g} / \mathrm{g}$ DCW, respectively. Other KF-strains produced torularhodin as the main pigment and its total yield varied from $0.4-1.4 \mathrm{mg} / \mathrm{L}$ and its accumulation in the cells was in the range of $31.2-121.0 \mu \mathrm{g} / \mathrm{g}$ DCW.

Due to demand for more effective carotenoidproducing strains, many researchers have been involved for screening of new yeast varieties.

\section{Conclusion}

Five new carotenoid strains were obtained by selection of $40 \mathrm{KF}$ samples isolated from different vegetative parts of vine. KF-104 isolate was considered as the best pigment-producing yeast that achieved significant carotenoid overproduction. The yeast indicated maximum carotenoid accumulation (1.15 mg/g DCW) and yield (9.69 mg/L). The next study is oriented on optimization of physiological conditions with the aim to improve production of selected pigments.

\section{Acknowledgement}

This article was created with the support of the Ministry of Education, Science, Research and Sport of the Slovak Republic within the Research and Development Operational Programme for the project "University Science Park of STU Bratislava”, ITMS 26240220084, co-funded by the European Regional Development Fund.

\section{References}

Aksu Z, Eren AT (2005) Process Biochemistry 40: 2985-2991.

Bhosale P, Gadre RV (2001) Journal of Industrial Microbiology and Biotechnology 26: 327-332.

Bhosale P, Bernstein PS (2005) Applied Microbiology and Biotechnology 68: 445-455.

Britton G, Liaaen-Jensen S, Pfander H (2004) Carotenoids: handbook. Birkhäuser Verlag. Berlin.

Buzzini P, Martini A, Gaetani M, Turchetti B, Pagnoni UM, Davoli P (2005) Enzyme and Microbial Technology 36: 687-692.
Dworecka-Kaszak B， Kizerwetter-Swida M (2011) Mikologua Lekarska 18: 74-78.

El-Banna ABE, El-Raztek AMA, El-Mahdy AR (2012) Food and Nutrition Sciences 3: 627-633.

Folch J, Lees M, Stanley GHS (1957) Methods in Enzymology 3: 497-511.

Fores LCH, Ramirez Cordova JJ, Pelayo-Ortiz, C, Femat R, Herrera-Lopez EJ (2010) Process Biochemistry 53: $131-136$.

Frengova GI, Beshkova DM (2009) Journal of Industrial Microbiology \& Biotechnology 36: 163-180.

Furdíková K, Durčanská K, Macková K (2011) Vinič a víno 5: S4-6.

Furdíková K, Ďurčanská K, Macková K, Malík M (2012) Vinič a víno 2: $\mathrm{S} 7-8$.

Giovannucci E, Ascherio A, Rimm EB, Stampfer MJ, Colditz G, Willett WS (1995) Journal of the National Cancer Institute 87: 1767-1776.

Jin JM, Lee J, Lee YW (2010) FEMS Microbiology Letters 302: 197-202.

Kim J, DellaPenna D (2006). Proceedings of the National Academy of Science 103: 3474-3479.

Krinsky NI, Johnson EJ (2005) Molecular Aspects of Medicine 26: 459-51.

Maldonade IR, Rodríguez-Amaya DB, Scamparini ARP (2008) Food Chemistry 107: 145-150.

Mantzouridou F, Roukas T, Kotzekidou (2002) Biochemical Engineering Journal 10: 123-135.

Mayne ST (1996) FASEB Journal 10: 690-701.

Nasri-Nasravadi MR, Razavi SH (2010) Journal of Bioscience and Bioengineering 109: 361-368.

Reiss E, Shadomy JH, Marshall LG (2012) Fundamental Medical Mycology. Wiley-Blackwell.

Ribeiro B, Barreto D, Coelho M (2011) Food Biop Tech 4: 693-701.

Schmidt-Dannert C (2000) Curr Opin Biotechnol 11: 255-261.

Tinoi J, Rakariyatham N, Deming RL (2005) Process Biochemistry 40: 2551-2557.

Voutilainen S, Nurmi T, Mursu J, Rissanen TH (2006) The American Journal of Clinical Nutrition 83: 1265-1271.

Xu F, Yuan QP, Zhu Y (2007) Process Biochemistry 42: 289-293.

Ye VM, Bhatia SK (2012) Biotechnology Letters 34: 1405-1414.

Yurkov AM, Vustin MM, Tyaglov BV, Maksimova IA, Sinekoiy SP (2008) Microbiology 77: 1-6. 